\title{
Diagnosis and Therapeutics of Pulmonary Arteriovenous Fistula in Childhood. Case Report and Review of the Literature
}

\author{
Roberto Bartolomeu Gianisella, Raul Ivo Rossi Filho, Paulo Zielinsky
}

Porto Alegre, RS - Brazil

\begin{abstract}
We report the case of a 3-year-old female patient, who, since birth, had cyanosis difficult to explain with usual diagnostic tests. The only findings on physical examination were cyanosis and clubbing of her fingers. Chest computerized tomography showed images of excessive attenuation in the right lung, which resembled arteriovenous fistulae that were later confirmed on cardiac catheterization. The fistulous trajectories were then embolized with 7 Gianturco coils, which resulted in an immediate increase in the arterial saturation of blood oxygen.
\end{abstract}

During the embryological development of the vascular system, which occurs between the $5^{\text {th }}$ and $10^{\text {th }}$ weeks of intrauterine life, a continuous differentiation of the vascular bed occurs, resulting in the creation of separate arterial and venous channels, interconnected by capillaries. When a mistake or halt occurs in this process of vascular differentiation, vascular malformations will appear at different anatomical sites and with variable morphology (fig. 1), depending on the stage of differentiation ${ }^{1}$. We report the diagnosis and interventional therapeutics of arteriovenous fistulae in the lungs of a 3-year-old child.

Pulmonary arteriovenous fistulae are characterized by right-to-left shunt of variable magnitude, and the effect of these communications depends on the size of the vessels involved. If the anastomoses affect peripheral arterioles and venules, a small telangiectasia will result, and it usually remains small, not causing hemodynamic alterations in the pulmonary circulation. If larger veins and arteries are affected or if massive involvement of the pulmonary capillaries takes place, an increase in the size of the vessels may occur ${ }^{2}$, resulting in severe hemodynamic alterations. Arterial desaturation of oxygen, cyanosis, clubbing of the fingers, and po-

Instituto de Cardiologia do Rio Grande do Sul/Fundação Universitária de Cardiologia

Mailing address: Roberto Gianisella - Unidade de Pesquisa do IC/FUC - Av Princesa Isabel, 395 - 90620-001 - Porto Alegre, RS, Brazil - E-mail: pesquisa@cardnet.tche.br

English version by Stela Maris C. e Gandour lycythemia may occur, secondary to the intrapulmonary shunt. Multiple neurological sequelae have been reported due to a variety of infectious, embolic, and hemorrhagic complications $^{3-5}$.

The etiology of pulmonary arteriovenous fistulae may be congenital or acquired. The congenital form has 2 varieties: a) cavernous angioma, usually fed by 1 or more tortuous and dilated branches of the pulmonary artery and b) capillary telangiectasia, which forms a net of capillaries and is usually associated with hereditary hemorrhagic telangiectasia ${ }^{6}$ or Rendu-Osler-Weber syndrome. This syndrome is an autosomal dominant vascular dysplasia with variable penetrance, has multiple telangiectasias, and is characterized by recurring hemorrhages. The levels of the coagulation factors are normal and the coagulation mechanism is intact. Approximately $1 / 3$ of the patients diagnosed with this syndrome presents pulmonary vascular malformations. Some studies together with the scientific division of the Hereditary Hemorrhagic Telangiectasia (HHT) Foundation International, Inc. reached a clinical consensus on the diagnostic criteria for this disease; 4 criteria should be sought: epistaxis, telangiectasias, visceral lesions, and a compatible familial history. The diagnosis of RenduOsler-Weber disease is established if 3 of the above-cited criteria are present. If less than 2 criteria are present, the diagnosis of the disease is very unlikely, even though children of parents affected should be considered at risk due to the fact that the penetrance varies with age. The clinical investigation of our patient showed only 1 of the cited criteria, which was pulmonary telangiectasia, making the diagnosis of Rendu-Osler-Weber syndrome unlikely.

Pulmonary arteriovenous fistula in its acquired form usually occurs in juvenile cirrhosis, but has also been reported in patients with metastases of thyroid carcinoma and pulmonary schistosomiasis. In the latter, the pulmonary arteriovenous fistula occurs because of the vascular neoformation secondary to chronic vasculitis triggered by Schistosoma eggs or their metabolic or degrading products. 


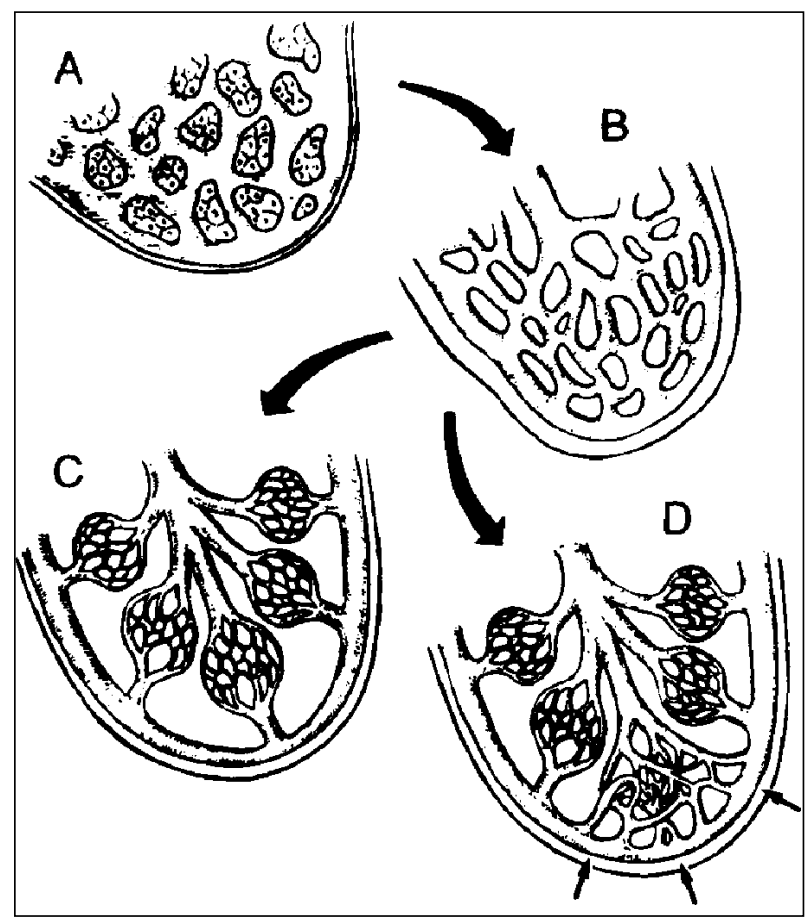

Fig. 1 - Normal stages of vascular development according to Woolard ${ }^{1}$ : a) primitive mesenchyma; b) differentiation in plexiform structures; c) disappearance of the primitive elements and differentiation into vascular structures; d) inadequate development during the embryogenesis of the vascular system with persistence of the primitive vascular communications or arteriovenous malformations (small arrows).

\section{Case report}

The patient is a 3-year-old white female child with progressive clubbing of her fingers and cyanosis since birth. Physical examination did not disclose other abnormalities and no additional clinical symptoms were reported. Analysis of the arterial gases at room temperature showed $\mathrm{pH}=7.5$; $\mathrm{PCO}_{2}=26 \mathrm{~mm} \mathrm{Hg} ; \mathrm{PO}_{2}=36 \mathrm{mmHg} ; \mathrm{CO}_{2} \mathrm{~T}=20.4 \mathrm{mmol} / \mathrm{L} ;$ bi carbonate $=19.4 \mathrm{mEq} / \mathrm{L}$; saturation of $\mathrm{O}_{2}=75 \%$. Hematocrit $=$ $48 \% ; \mathrm{Hb}=15.5 \mathrm{~g} / \mathrm{dL} ; \mathrm{MCV}=91$. Electrocardiography, echocardiography, and total abdominal echography were within the normal range. The chest $X$-ray showed an interstitial infiltrate in the right base and perihilar regions.

Continuing with the investigation, a chest computerized tomography was performed and revealed images of excessive attenuation in the right lung, close to the posterior wall, with confluence of the vessels. These alterations raised the possibility of pulmonary arteriovenous fistulae (fig. 2).

Considering that pulmonary arteriovenous fistulae might be present, a cardiac catheterization was performed to elucidate the diagnosis. The angiographic study showed a vascular net with diffuse malformations in the right middle and inferior pulmonary lobes (fig. 3 and 4). Pressures in the cardiac cavities were as follows (in $\mathrm{mmHg}$ ): $\mathrm{RA}=2$ (mean); $\mathrm{PA}=15$ (systolic), 9 (diastolic), 19 (mean); $\mathrm{LV}=77$ (systolic); Ao $=63$ (systolic), 38 (diastolic), 49 (mean). Pulmonary scintigraphy confirmed the results of catheterization.

Because the interventional therapy was chosen, pulmonary arteriovenous fistulae were embolized with catheteri-

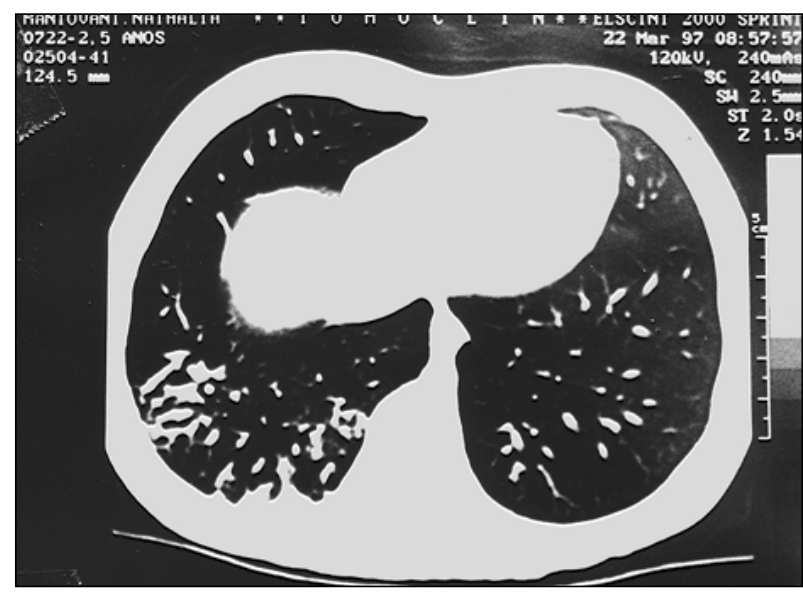

Fig. 2 - Computed tomography depicting images of excessive attenuation in the right lung close to the posterior wall with confluence of the vessels determining the possibility of pulmonary arteriovenous fistula.

zation with 7 Gianturco coils, sizes 3 and $5 \mathrm{~mm}$ (figs. 5 and 6). The immediate result was an increase in oxygen saturation from $90 \%$ to $98 \%$, with the patient sedated receiving oxygen by nasal catheter at the rate of $4 \mathrm{~L} / \mathrm{min}$ (figs. 5 and 6 ). At the time of hospital discharge, oxygen saturation measured at room temperature with the pulse oximeter was $90 \%$.

Prior to the embolization procedure of the fistulae, the right pulmonary artery was completely occluded with a balloon of an adequate size for investigating the existence of fistulae in the left lung. This hypothesis was discarded because the hemoglobin saturation suddenly increased from $90 \%$ to $100 \%$.

\section{Discussion}

Pulmonary arteriovenous fistula is not easily diagnosed routinely, due to its rarity and its unspecific findings on routine examinations. However, this diagnostic hypothesis should always be considered when examining children with cyanosis, in whom the initial tests do not detect cardiac abnormalities.

Two other alternatives in the diagnostic investigation, which were not used in the present case, are the calculation of the shunt through the saturations measured with catheterization in the different cardiac chambers ${ }^{7}$ and contrast echocardiography ${ }^{8,9}$, in which agitated saline solution, for example, can be injected in a peripheral vein. The microbubbles resulting from this process and detected in the left atrium determine a right-to-left shunt through the lungs. The capillary alveolar filter does not allow the passage of these microbubbles.

Tc-99m MAA total body imaging ${ }^{10,11}$ follows the same principle, because the macroaggregates of albumin labeled with technetium- 99 measure from 20 to $60 \mathrm{~mm}$, but the diameter of the pulmonary capillary bed is smaller than $15 \mathrm{~mm}$. Contrast medium uptake in other organs, in addition to the lungs, would show the presence of the shunt, and the pulmonary area with no radionuclide would delimitate its site ${ }^{12}$. 


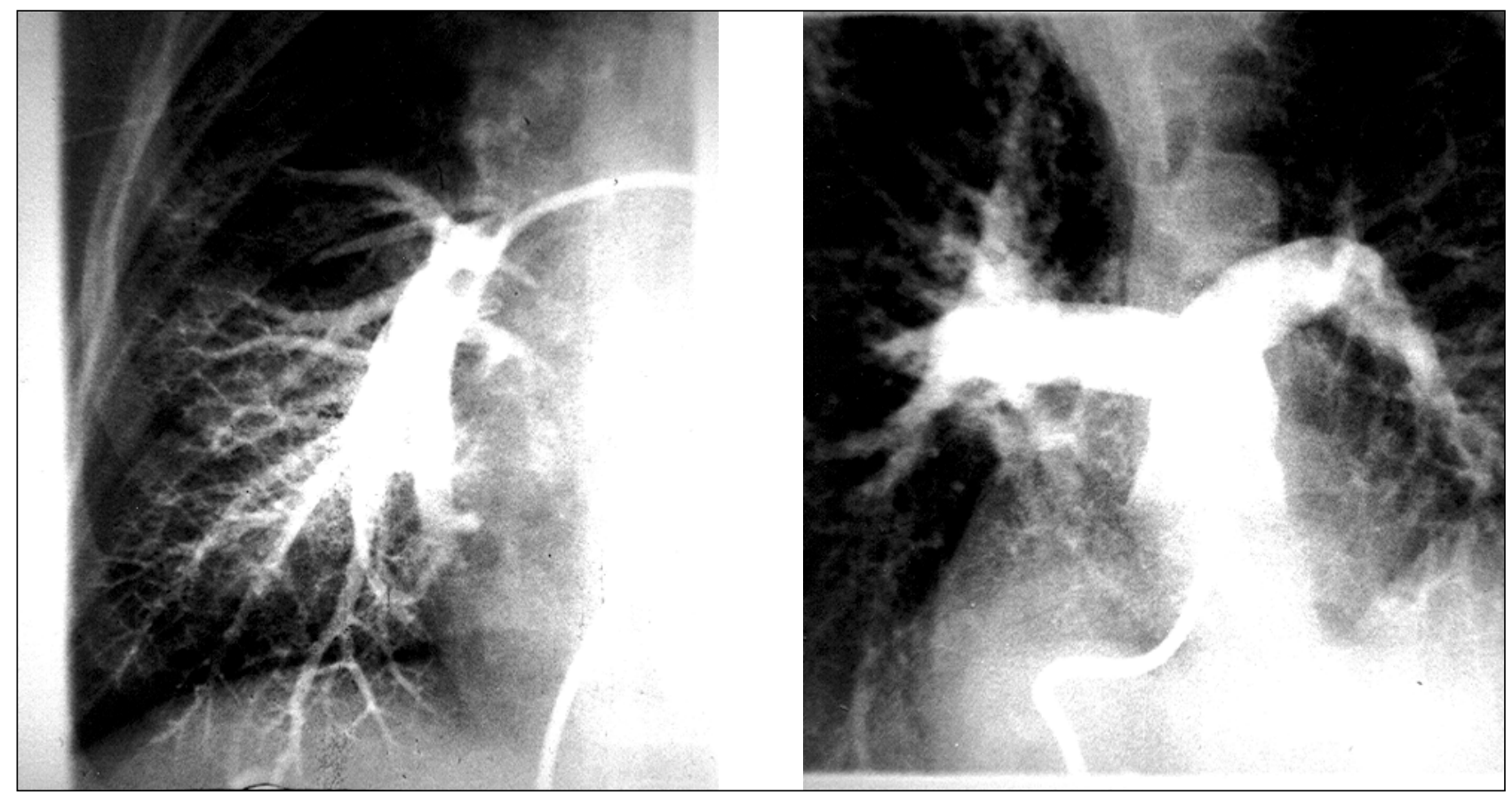

Figs. 3 and 4 - Pulmonary arteriography showing multiple pulmonary fistulae.
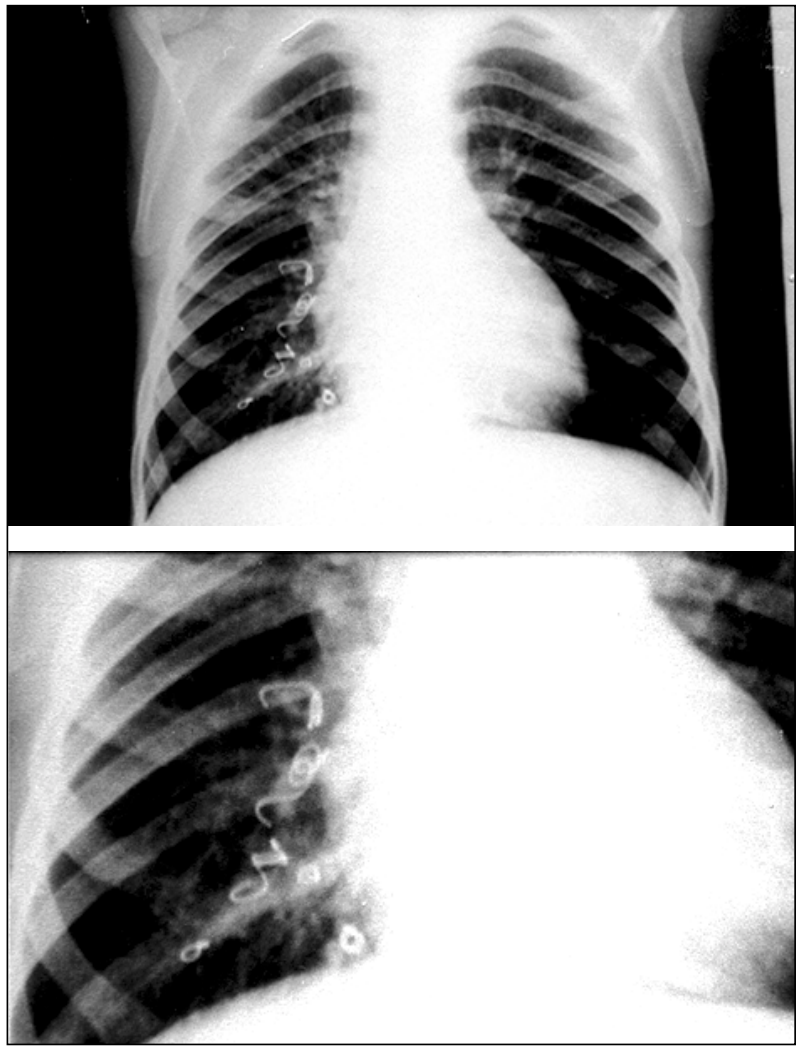

Figs. 5 and 6-Chest X-ray showing the coils (left) and one widened image of the right inferior lobe (right).
In the case we report, the diagnosis was established by chest spiral computed tomography, pulmonary scintigraphy, and selective pulmonary angiography.

Interferon has been suggested as a less invasive therapeutical approach, but, until the present time, its efficacy for the treatment of pulmonary arteriovenous fistula has not been scientifically confirmed.

Another alternative would be occlusion of each pulmonary lobe with a balloon, and concomitant assessment of blood saturation, therefore checking whether selective embolizations with detachable balloon ${ }^{13-15}$ could replace pneumectomy ${ }^{16}$. Embolization with coils has also been successfully used ${ }^{17-20}$, even in the patients with telangiectasia ${ }^{21}$.

Chest computed tomography performed after the procedure could serve to confirm the success of embolization ${ }^{22}$, and the quantification of the percentage of the reduction in the shunt could be done with pulmonary scintigraphy with Tc-99m MAA ${ }^{10,11}$, comparing the rate of short-circuit established prior to the procedure.

In our case, we chose the interventional approach, with multiple embolizations with coils, because of the great number of fistulous trajectories, and the result was considered satisfactory. Andersen et al ${ }^{23}$ and Shioyia et al ${ }^{24}$ had similar results.

Finally, it is worth emphasizing that blood saturation may decrease with time as a consequence of opening new fistulae because of the progressive character of the disease. 


\section{References}

1. Woolard HH. The development of the principal arterial stems in the forelimb of the pig. Contemp Embryol 1992; 14: 139.

2. Moyer JH, Glantz G. Pulmonary arteriovenous fistulas, physiologic and clinical considerations. Am J Med 1962; 32: 417-35.

3. Press OW, Ramsey, PG. Central nervous system infections associated with hereditary hemorrhagic telangiectasia. Am J Med 1984; 77: 86-92.

4. Boczko ML. Neurological implications of hereditary hemorrhagic telangiectasia. J Nerv Ment Dis 1964; 139: 525-36.

5. Merland JJ, Djindjian R. Manifestations cérébrales de la maladie de RenduOsler. J Neuroradiol 1974; 1: 257-85.

6. Batinica S, Gagro A, Bradic I, et al. Congenital pulmonary arteriovenous fistula: a rare cause of cyanosis in childhood. Thorac Cardiovasc Surg 1991; 39: 105-6.

7. Shapiro JL, Levien MG, Latson LA, et al. Diffuse pulmonary arteriovenous malformations (angiodysplasia) with unusual histologic features. Pediatric Pulmology 1996; 21: 255-61.

8. Van Hare GF, Silverman NH. Contrast two-dimensional echocardiography in congenital heart disease: techniques, indications and clinical utility. J Am Coll Cardiol 1989; 13: 673-86

9. Hernandez A, Strauss AW, McKnight R, et al. Diagnosis of pulmonary arteriovenous fistula by contrast echocardiography. J Pediatrics 1978; 93: 258-61.

10. Lu G, Shih WJ, Xu SY, et al. TC-99m MAA total-body imaging to detect intrapulmonary right-to-left shunts and to evaluate the therapeutic effect in pulmonary arteriovenous shunts. Clin Nuclear Med 1996; 21: 197-202.

11. Chilvers ER, Peters AM, George P, et al. Quantification of right to left shunt through pulmonary arteriovenous malformations using $99 \mathrm{Tc} \mathrm{m}$ albumin $\mathrm{mi}-$ crospheres. Clinical Radiology 1988; 39: 611-4.

12. Lewis AB, Gates GF, Slanley P. Echocardiography and perfusion scintigraphy in the diagnosis of pulmonary arteriovenous fistula. Chest 1978; 73: 675-7.

13. Terry PB, White RI, Barth KH, et al. Pulmonary arteriovenous malformations. Phy- siologic observations and results of therapeutic ballon embolization. N Eng J Med 1983; 308: 1197-200.

14. Goergen SK, Sacharias NR. Pulmonary arteriovenous malformations: pathology, clinical features and treatment with ballon and coil oclusion. Australas Radio 1992; 36: 222-9.

15. Costa GPR, Cukier A. Pulmonary arteriovenous fistulae: treatment by embolization. J Pneumol 1986; 12: 180-3.

16. Jatene FB, Pêgo F. Tratamento cirúrgico das fístulas arteriovenosas pulmonares J Pneumol 1990; 16: 9-12

17. Gianturco C, Anderson JH, Wallace S. Mechanical devices for arterial occlusion. Am J Roentgenol 1975; 124: 428-35.

18. Jackson JE, Whyte MKB, Allison DJ, et al. Coil embolization of pulmonary arteriovenous malformations. Cor Vasa 1990; 32: 91-6.

19. Hartnell GG, Jackson JE, Allison DJ. Coil embolization of pulmonary arteriovenous malformations. Cardiovasc Intervent Radiol 1990; 13: 347-50.

20. Hartnell GG, Allison DJ. Coil embolization in the treatment of pulmonary arteriovenous malformations. J Thorac Imag 1989; 4: 81-5.

21. Dutton JA, Jackson JE, Hughes JM, et al. Pulmonary arteriovenous malformations: results of treatment with coil embolization in 53 patients. Am J Roentg 1995; 165: 1119-25

22. Remy J, Remy-Jardim M, Wattinne L, Deffontaines C. Pulmonary arteriovenous malformations: evaluation with $\mathrm{CT}$ of the chest before and after treatment. Radiology 1992; 182: 809-16.

23. Andersen PE, Kjeldsen AD, Oxhj H, et al. Embolotherapy for pulmonary arteriovenous malformations in patients with hereditary hemorrhagic telangiectasia. Acta Radiol 1988; 39: 723-6.

24. Shioya T, Sano M, Kagaya M, et al. Transcatheter embolization of pulmonary arteriovenous malformations in Rendu-Osler-Weber disease. Respirology, 1988 3: $277-80$ 